\title{
Bronquiolite Respiratória associada à Doença Intersticial Pulmonar e Histiocitose das Células de Langerhans: estudo de caso
}

\author{
Respiratory bronchiolitis interstitial lung disease and Langerhans Cell Histiocytosis: case \\ study
}

Bronquiolitis respiratoria asociada a enfermedad pulmonar intersticial e histiocitosis de células de Langerhans: un estudio de caso

Ricardo Andre Medeiros Negreiros ${ }^{1 *}$, Bernardo Rosado Negreiros Gadelha Simas ${ }^{2}$, Victor José Negreiros de Sá Rosado², Giulia Palitot de Oliveira Lima Nunes ${ }^{3}$, Pedro Paulo Feitosa Amorim ${ }^{4}$, Luís Eduardo Negreiros d'Assunção ${ }^{1}$, Fernando José Pinho Queiroga ${ }^{5}$, Viviane Rosado Negreiros d'Assunção ${ }^{3}$.

\section{RESUMO}

Objetivo: Relatar um caso notável de Bronquiolite Respiratória associada à Doença Intersticial Pulmonar (RB-ILD) cursando com Histiocitose das Células de Langerhans (LCH). Detalhamento do Caso: Paciente masculino, 57 anos, obeso, sedentário, com carga tabágica de 80 maços-ano. Em consulta de rotina, realizou tomografia computadorizada de tórax (TC) que revelou pequenas opacidades nodulares de aspecto inespecífico, além do diagnóstico de enfisema pulmonar centrolobular. Após 8 meses, compareceu ao pneumologista com tosse persistente e sem alterações no exame físico. Feita nova TC, evidenciou-se múltiplas opacidades nodulares de contornos irregulares acometendo difusamente o parênquima de ambos os pulmões, predominando nos lobos superiores e médio, com suspeita de envolvimento neoplásico secundário. Feita biópsia pulmonar, observou-se infiltrado inflamatório nodular, com bordas irregulares, em distribuição peribronquiolar e subpleural, composto por histiócitos pigmentados e agregados linfoides em meio a fibrose. $O$ parênquima adjacente revelou bronquiolite respiratória. $\mathrm{O}$ exame imuno-histoquímico revelou positividade para células CD1a+ em alguns nódulos. Os achados foram compatíveis com RB-ILD e LCH, sendo estas doenças de etiologia raras que se apresentam nos exames de imagem similares a outras afecções pulmonares. Considerações Finais: Por tratar-se de condições raras, é necessário que seja feita a devida investigação para se evitar diagnósticos incorretos e tratamentos inadequados.

Palavras-chave: Bronquiolite, Histiocitose de Células de Langerhans, Doenças Respiratórias, Diagnóstico.

\begin{abstract}
Objective: To report a remarkable case of respiratory bronchiolitis associated with interstitial lung disease (RB-ILD) and Langerhans Cell Histiocytosis (LCH). Case Report: Male patient, 57 years old, obese, sedentary, with smoking load of 80 packs per year. During a routine consultation, he underwent a chest computed tomography (CT) scan that revealed small nodular opacities of nonspecific aspect, in addition to the diagnosis of centrilobular pulmonary emphysema. After 8 months, the patient presented to a pulmonologist with persistent cough and no changes in the physical examination. A new CT was performed, revealing multiple nodular opacities with irregular contours diffusely affecting the parenchyma of both lungs, predominantly in the upper and middle lobes, with suspicion of secondary neoplastic involvement. A lung biopsy revealed a nodular inflammatory infiltrate, with irregular borders, in a peribronchiolar and subpleural distribution, composed of

1 Universidade Federal da Paraíba (UFPB), João Pessoa - PB. *E-mail: ricardoandrenegreiros@gmail.com

2 Universidade Potiguar (UNP), Natal - RN.

${ }^{3}$ Centro Universitário de João Pessoa (UNIPÊ), João Pessoa - PB.

${ }^{4}$ Faculdade Pernambucana de Saúde (FPS), Recife - PE.

5 Universidade de Pernambuco (UPE), Recife - PE.
\end{abstract}

SUBMETIDO EM: 2/2021

ACEITO EM: 3/2021

PUBLICADO EM: 3/2021 
pigmented histiocytes and lymphoid aggregates in the midst of fibrosis. The adjacent parenchyma revealed respiratory bronchiolitis. Immunohistochemical examination revealed positivity for CD1a+ cells in some nodules. The findings were compatible with RB-ILD and LCH, these being diseases of rare etiology that present on imaging exams similar to other lung diseases. Final Considerations: Since these are rare conditions, it is necessary that they be properly investigated to avoid misdiagnosis and inappropriate treatment.

Key words: Bronchiolitis, Langerhans-Cell Histiocytosis, Respiratory Tract Diseases, Diagnosis.

\section{RESUMEN}

Objetivo: Reportar un caso notable de bronquiolitis respiratoria asociada a enfermedad pulmonar intersticial (RB-ILD), asociada a Histiocitosis de Células de Langerhans (HCL). Detalle del Caso: Paciente varón de 57 años, obeso, sedentario, con una carga de tabaco de 80 paquetes al año. Durante una consulta rutinaria, se le realizó una tomografía computarizada (TC) de tórax que reveló pequeñas opacidades nodulares de aspecto inespecífico, además del diagnóstico de enfisema pulmonar centrilobular. Después de 8 meses, el paciente se presentó al neumólogo con tos persistente y sin cambios en la exploración física. Una nueva TC reveló múltiples opacidades nodulares de contornos irregulares que afectaban de forma difusa al parénquima de ambos pulmones, predominantemente en los lóbulos superiores y medios, con sospecha de afectación neoplásica secundaria. Una biopsia pulmonar reveló un infiltrado inflamatorio nodular, de bordes irregulares, en una distribución peribronquiolar y subpleural, compuesto por histiocitos pigmentados y agregados linfoides en medio de la fibrosis. El parénquima adyacente reveló una bronquiolitis respiratoria. El examen inmunohistoquímico reveló positividad para las células CD1a+ en algunos nódulos. Los hallazgos fueron compatibles con la RB-ILD y la HCL, siendo éstas enfermedades de etiología rara que se presentan en las pruebas de imagen de forma similar a otras enfermedades pulmonares. Consideraciones Finales: Debido a que se trata de condiciones raras, es necesario que se realice una investigación adecuada para evitar diagnósticos erróneos y tratamientos inadecuados.

Palabras clave: Bronquiolitis, Histiocitosis de Células de Langerhans, Enfermedades Respiratorias, Diagnóstico.

\section{INTRODUÇÃO}

A Histiocitose das Células de Langerhans (LCH) é uma doença com mutações associadas ao câncer, sendo uma patologia neoplásica (não maligna), que tem etiologia indefinida e com várias lesões nodulares e infiltrativas, tendo a possibilidade de causar dano aos tecidos vizinhos. Seu envolvimento neoplásico tem origem mieloide caracterizado pela proliferação clonal de células CD1a+/CD207+ e das Células de Langerhans (LC), que tem genoma e fenótipo alterados. Os pulmões, ossos, a pele e a pituitária são os principais sítios acometidos em adultos (GIRSCHIKOFSKY M, et al., 2013; MONSEREENUSORN C e RODRIGUEZ-GALINDO C, 2015)

Sua manifestação pulmonar, a Histiocitose das Células de Langerhans do Pulmão (PLCH), pertence a um grupo raro de doenças císticas, tem natureza proliferativa e patogênese associada a um elemento inflamatório reativo. A prevalência da doença em adultos é de 1 a cada 1 milhão de pessoas, com faixa etária mais comum entre os 20 e 40 anos, sendo mais frequente em homens. Cerca de $95 \%$ dos pacientes com PLCH são fumantes, apesar dos mecanismos que vinculam o cigarro à doença não serem claros (GIRSCHIKOFSKY M, et al., 2013; RADZIKOWSKA E, 2017)

O pulmão, após receber o infiltrado de células dendríticas especializadas (células de Langerhans), desenvolve uma cascata inflamatória com vários estágios de disfunção do órgão (DEMARTINO E; et al., 2016). No momento inicial da doença, percebem-se nódulos com parede espessa, enquanto que nas fases avançadas há o desenvolvimento de cistos com paredes finas (MONSEREENUSORN C e RODRIGUEZGALINDO C, 2015). Tais cistos podem chegar até 15 milímetros, com a possibilidade de evoluírem com hiperinflamação e fibrose em estilo de favo de mel (DEMARTINO E, 2016).

Os sintomas percebidos nas fases iniciais da doença são genéricos ou inexistentes, com difícil detecção de sinais patológicos significantes no exame físico. Do ponto de vista laboratorial, há elevados marcadores inflamatórios séricos. O uso de técnicas como a broncoscopia ainda não torna viável estabelecer o diagnóstico da doença, apesar de se detectar quantidade elevada de CD1a (RADZIKOWSKA E, 2017). 
Para diagnóstico radiológico, a radiografia de tórax é pouco útil devido à dificuldade em se identificar as múltiplas lesões (RADZIKOWSKA E, 2017). A Tomografia Computadorizada de alta resolução (TC) é a mais importante ferramenta de visualização, percebendo-se a presença dos nódulos bilateralmente, com padrão reticulonodular e formação de "bolhas", predominantemente nos lobos médios e superiores do pulmão (GIRSCHIKOFSKY M, et al., 2013; MONSEREENUSORN C e RODRIGUEZ-GALINDO C, 2015).

O diagnóstico padrão ouro é baseado no exame histológico e imunofenotípico da biópsia da lesão, que apresentam células de Langerhans com CD1a positivos ou Langerina (GIRSCHIKOFSKY M, et al., 2013). Histologicamente, há abundância de $\mathrm{CL}$ e números variáveis de linfócitos, macrófagos pigmentados, monócitos, células plasmáticas e eosinófilos, estes últimos infiltrados de forma abundante, formando granulomas (DEMARTINO E, et al., 2016).

A Bronquiolite Respiratória (RB) é um marcador histológico que pode ser identificado na grande maioria de indivíduos fumantes, e recebe esse nome devido diversas mudanças inflamatórias causadas pela fumaça do tabaco nos bronquíolos distais e respiratórios, com infiltrações variáveis ao redor do tecido peribronquiolar (PAPPAS K, 2011).

Os principais achados patológicos na RB são aglomerados de macrófagos alveolares levemente dourados ("macrófagos do fumante") nos lúmens dos bronquíolos respiratórios, ductos alveolares e alvéolos circundantes. Alguns dos bronquíolos e das paredes dos alvéolos adjacentes também demonstram um infiltrado inflamatório intersticial crônico leve, bem como fibrose intersticial e hiperplasia das células epiteliais alveolares sobrepostas (CHURG A, et al., 2010).

No que tange aos sintomas, vale ressaltar que maioria esmagadora dos pacientes são assintomáticos, embora com leve, mas subclínico, prejuízo fisiológico (WALSH SLF, et al., 2015). A Bronquiolite Respiratória associada a Doença Intersticial do Pulmão (RB-ILD) é uma doença pulmonar inflamatória rara. É caracterizada por falta de ar e tosse, anormalidades da função pulmonar de padrão obstrutivo, restritivo ou misto, frequentemente acompanhada por enfisema centrolobular relacionado ao tabagismo. O início da RBILD é geralmente insidioso, com dispneia ao esforço, sibilos presentes na ausculta e tosse persistente (SIEMINSKA A e KUZIEMSKI K, 2014).

Células dendríticas CD1a+ são um agrupamento de células específicas que fazem parte do recrutamento imunológico e que se apresentam com maior expressividade em fumantes (LA ROCCA G, et al., 2004; LIAO SX, et al., 2015). Há ainda uma correlação entre citocinas pró-inflamatórias, que atuam nas células CD1a+ no pulmão, com uma resposta do inflamassoma induzida pela inalação de nanopartículas de carbono negro, encontradas no fumo, intensificando a inflamação e obstrução pulmonar (PAIVA-OLIVEIRA EL, et al., 2012; YUAN X, et al., 2019).

Aspectos como idade avançada, nódulos de grande tamanho, margem espiculada, irregularidade na parede e fumantes compulsivos estão associados à um quadro de alto risco. Manifestações clínicas que merecem uma maior atenção são: tosses novas, hemoptise, dispneia, pneumonia recorrente em um local específico, exacerbação de enfisema pulmonar, perda ponderal, anorexia e fadiga. A TC é usada quando há suspeita ou confirmação de CPCNP (NASIM F, et al., 2019).

Além disso, pela grande heterogeneidade e complexidade dos cânceres de pulmão, conhecer suas classificações e particularidades se tornou imprescindível (SOUSA VMLD e CARVALHO L, 2018). As lesões do CPCNP podem ser vistas como massas localizadas centralmente ou na periferia, invadindo estruturas mediastinais ou a parede torácica. As margens dos tumores variam de lisas, lobuladas, irregulares e espiculadas.

Elas podem ser uniformemente solidas ou até apresentar necrose central e cavitação. Os tumores também podem apresentar aspectos de doenças infecciosas, e serem vistos como uma área de consolidação, de vidro fosco, ou uma combinação de ambos, estas sendo mais presentes nos adenocarcinomas. Independentemente da aparência radiológica do câncer suspeito, obter a biópsia desse tecido é extremamente necessário (PURANDARE NC e RANGARAJAN V, 2015). 
Além disso, os tumores metastáticos apresentam uma expressão distinta do padrão de marcadores CK7 e CK20, além de expressão dos marcadores do órgão associado, reforçando a análise imuno-histoquímica como sendo imprescindível para o diagnóstico correto de uma neoplasia pulmonar (ZHENG M, 2016). Este estudo tem como objetivo relatar um caso notável de Bronquiolite Respiratória associada à Doença Intersticial Pulmonar (RB-ILD) cursando com Histiocitose das Células de Langerhans (LCH)

\section{DETALHAMENTO DO CASO}

Homem, 57 anos, obeso, sedentário, tabagista há 40 anos, com carga tabágica de 80 maços-ano, etilista crônico, com histórico de cirurgia bariátrica há 11 anos. Apresentou-se em consulta de rotina, sem queixas clínicas, durante a qual realizou TC de tórax. O exame revelou a presença de pequenas opacidades nodulares de aspecto inespecífico, em ambos os pulmões, sendo as maiores no segmento apical do lobo superior do pulmão direito $(5 \mathrm{~mm})$, no segmento anterior do lobo superior do pulmão direito $(4 \mathrm{~mm})$ e no segmento apical do lobo inferior do pulmão esquerdo $(5 \mathrm{~mm})$. Foi diagnosticado enfisema pulmonar centrolobular e parasseptal, além de áreas de aprisionamento aéreo esparsas bilateralmente que podem estar relacionadas a doença das pequenas vias aéreas (Figura 1).

Figura 1 - Imagem de TC demonstrando pequenos elementos opacos nodulares centrolobulares de aspecto inespecífico.

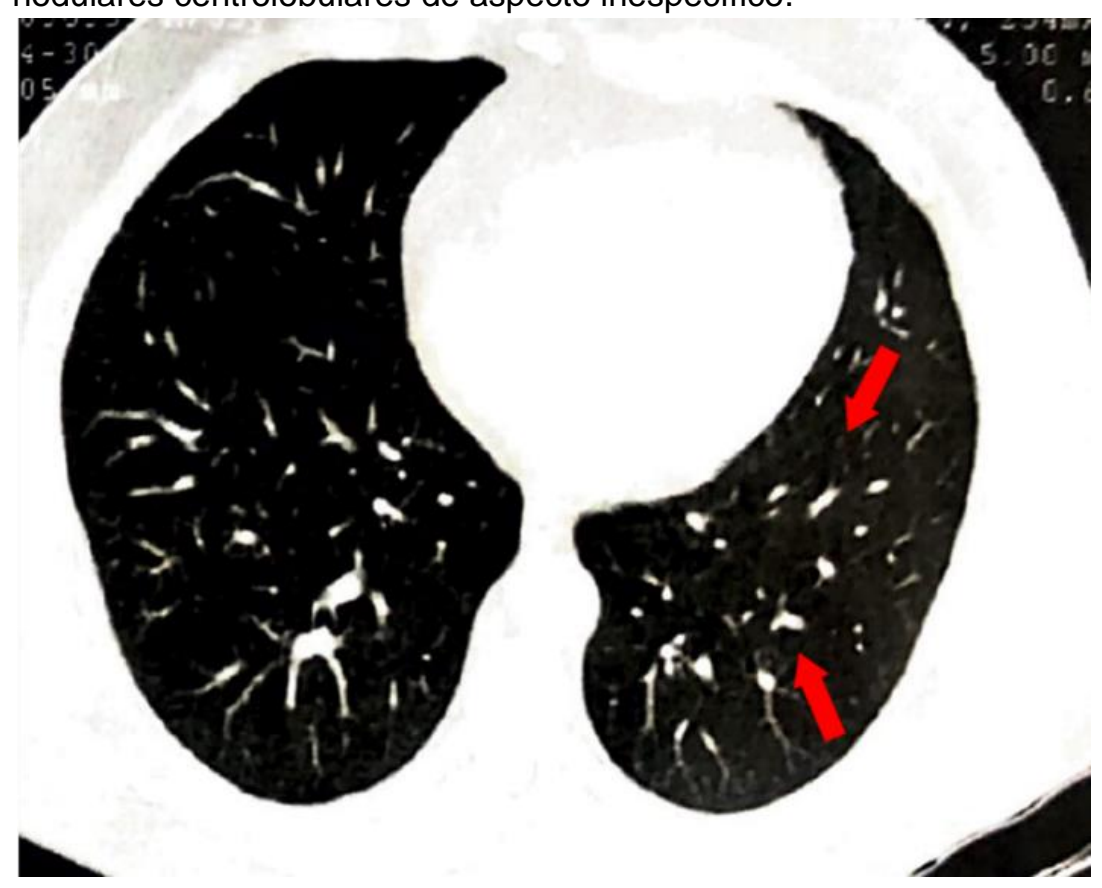

Fonte: Negreiros RAM, et al., 2021.

Na ocasião encontrava-se eupneico, acianótico, tórax atípico, sem abaulamento ou depressões, ausência de cicatrizes cirúrgicas ou circulação colateral, ausculta com murmúrio vesicular presente, simétrico e sem ruídos adventícios.

Após 8 meses, o paciente apresentou quadro de tosse seca, com pigarro, crônica, de início gradual, sem outras manifestações clínicas como febre, dispneia, hemoptise, epistaxe ou perda de peso. Informou antecedentes familiares de carcinoma de próstata e mama.

Foi submetido a outra TC de tórax que identificou a presença de múltiplas opacidades nodulares de contornos irregulares, por vezes espiculados, acometendo difusamente o parênquima de ambos os pulmões, predominando nos lobos superiores e médio sendo a maior delas identificada no segmento anterior do lobo superior direito, medindo $13 \mathrm{~mm}$ (Figura 2). Diante dos achados levantou-se a possibilidade de envolvimento neoplásico secundário. 
Figura 2 - Imagem de TC evidenciando presença de achados nodulares de contornos irregulares.

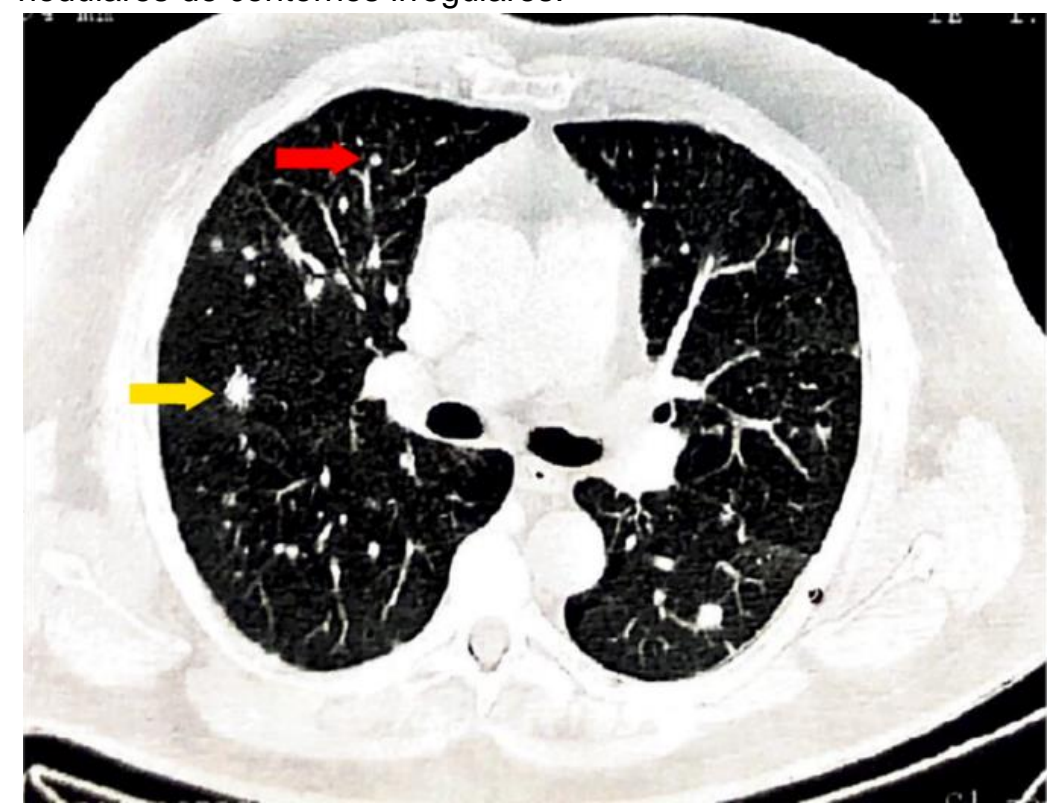

Fonte: Negreiros RAM, et al., 2021.

Considerando-se o histórico de tireoidectomia subtotal em decorrência nódulo, foi realizada uma reavaliação da tireoide através de ultrassonografia que confirmou a tiroidectomia parcial à direita e inexistência de alterações em lobo esquerdo. Também foi confirmada a avaliação histopatológica do nódulo removido, cuja conclusão foi pela existência de adenoma atóxico.

O paciente foi então submetido a uma broncofibroscopia, cujo exame histopatológico dos nódulos mostrou processo inflamatório crônico, macrófagos contendo hemossiderina e hiperplasia de células caliciformes. $\mathrm{Na}$ amostra, foi reportada ausência de neoplasia. O citopatológico, com coloração de Papanicolau, mostrou, por sua vez, material constituído por raras células epiteliais cilíndricas ciliadas sem atipias, além de vários macrófagos alveolares e linfócitos ocasionais, também apontando negativo para malignidade.

Realizou-se uma Tomografia por Emissão de Pósitrons em conjunto com Tomografia Computadorizada helicoidal multidetector (PET/CT), que, novamente, evidenciou os múltiplos nódulos pulmonares não calcificados, de contornos irregulares disseminados bilateralmente. Usando o traçador $18 \mathrm{~F}$-Fluordeoxiglicose (FDG-18F), verificou-se compatibilidade de tumor viável com discreto hipermetabolismo glicolítico em múltiplos nódulos pulmonares (Figura 3).

Figura 3 - Imagem de PET/CT que demonstra múltiplos nódulos calcificados.

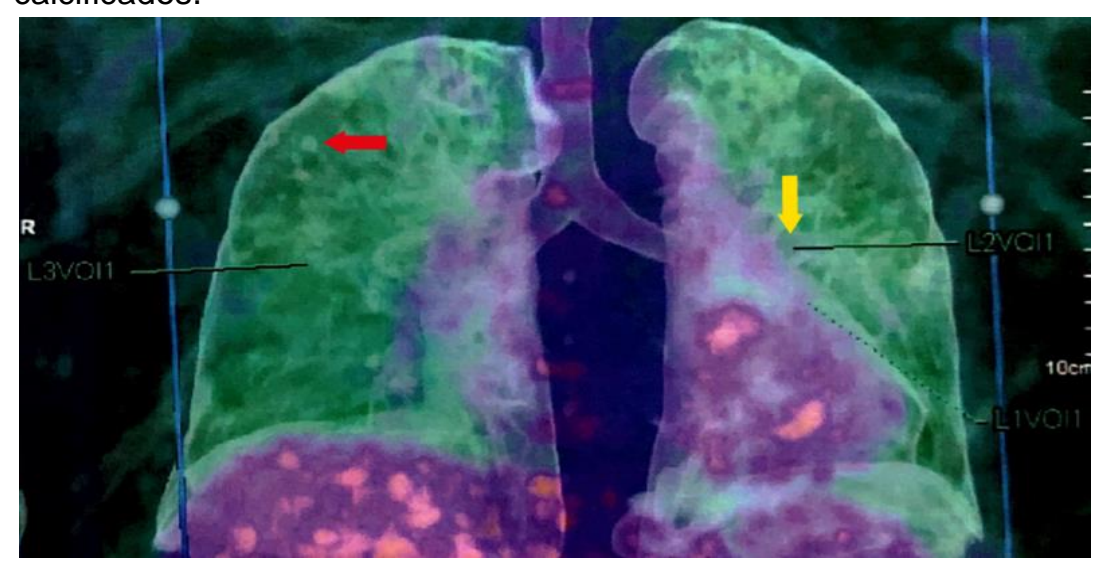

Fonte: Negreiros RAM, et al., 2021. 
Realizou-se uma biópsia pulmonar, e o segmento retirado mostrou infiltrado inflamatório nodular, com bordas irregulares, em distribuição peribronquiolar e subpleural, composto por histiócitos pigmentados, agregados linfoides e plasmócitos, em meio a fibrose. Foi revelado, no parênquima adjacente, bronquiolite respiratória, espessamento dos septos alveolares e alterações enfisematosas. O exame imuno-histoquímico revelou positividade para células CD1a+ em alguns nódulos.

Os achados, portanto, foram compatíveis com doença pulmonar intersticial associada à bronquiolite respiratória (RB-ILD), assim como, devido ao aumento numérico de células de Langerhans nos nódulos, de Histiocitose de Células de Langerhans, ocorrendo em background da RB-ILD. A conduta adotada foi a cessação total do consumo de tabaco e, após 12 meses, foi realizada nova TC de tórax que, em comparação ao estudo anterior, evidenciou importante diminuição no número e nas dimensões das lesões nodulares dos pulmões (Figura 4).

Figura 4 - Imagem de TC que demonstra redução do número de nódulos visíveis nos pulmões.
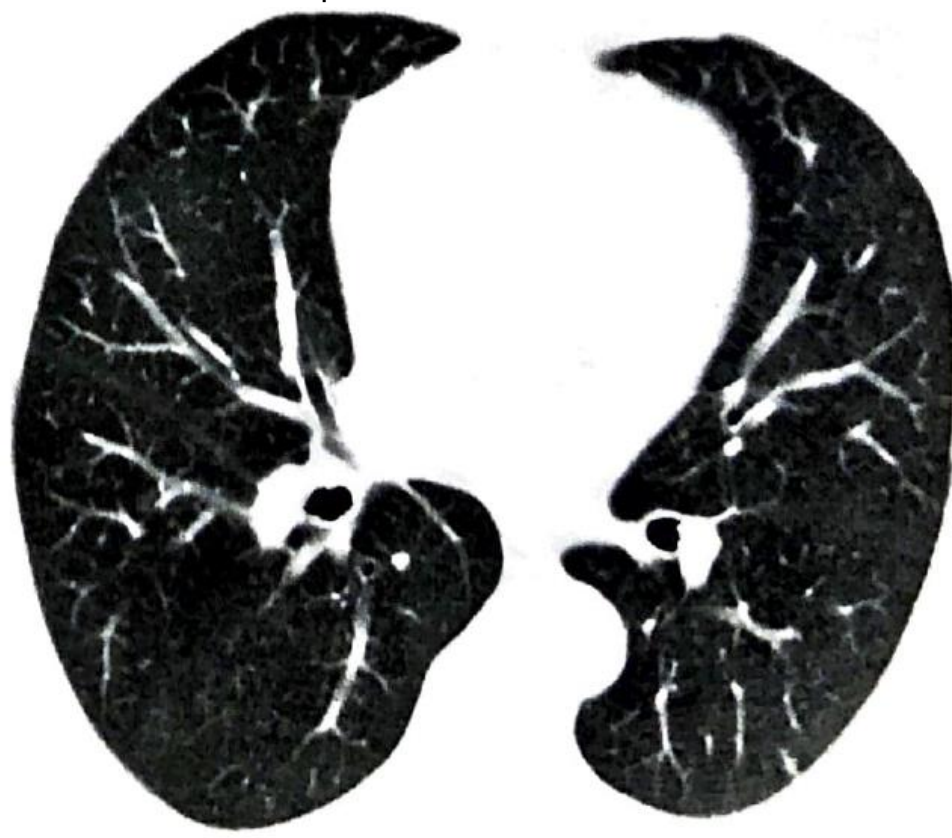

Fonte: Negreiros RAM, et al., 2021.

\section{DISCUSSÃO}

A LCH é uma doença pulmonar cística com patogênese associada a um elemento inflamatório reativo, ao passo que a RB-ILD é caracterizada por uma variação da bronquiolite respiratória com achados patológicos atípicos (RADZIKOWSKA E, 2017; WELLS AU, et al., 2003). Pessoas que têm RB- ILD, em geral, desenvolvem a LCH como doença associada (RODRIGUES SCS, et al., 2004). O paciente encontra-se dentro da faixa etária em que a RB- ILD é mais prevalente, entre a terceira e sexta década de vida, enquanto a PLCH é uma doença mais comum no período dos 20 aos 40 anos, apesar de se manifestar no caso em questão.

Em relação ao gênero do paciente, ambas as doenças são mais prevalentes no sexo masculino, sendo este caso um exemplo da frequência da doença em homens (GIRSCHIKOFSKY M, et al., 2013; SIEMINSKA A e KUZIEMSKI K, 2014). A literatura mostra que o tabagismo está amplamente ligado a bronquiolite respiratória e a LCH (CHURG A, et al., 2010; RODRIGUES SCS, et al., 2004).

O hábito de fumar é também o responsável pelo estabelecimento e desenvolvimento da fibrose pulmonar, bem como fragilidade do parênquima a outras doenças (KÄRKKÄINEN M, et al., 2017; MARGARITOPOULOS GA, et al., 2016). A destruição do parênquima pulmonar promovida pela Doença Pulmonar Obstrutiva Crônica (DPOC), juntamente com a fibrose, tendem a não modificar as taxas de fluxo, porém, reduzem a capacidade 
de difusão, provocando dispneia que tende a piorar com o tempo (FRANKS TJ e GALVIN JR, 2015). A RBILD pode ser vista em todos os fumantes e em cerca de $50 \%$ dos ex-fumantes, com resquícios que persistem anos após a cessação do hábito (KONOPKA KE e MYERS JL, 2018).

Além disso, 95\% dos pacientes com PLCH são tabagistas quando adultos e fumantes passivos quando crianças (RADZIKOWSKA E, 2017). O paciente em estudo tem um histórico de fumo de 80 maços/ano, acordando com a principal etiologia do seu diagnóstico. No caso apresentado, referiu-se tosse seca, sintoma comum nos casos de PLCH, que pode apresentar dispneia ao esforço, que evolui progressivamente à medida que o comprometimento pulmonar progrida (LORILLON G e TAZI A, 2017).

Apesar disso, cerca de $20 \%$ dos pacientes podem se apresentar assintomáticos devido ao não comprometimento significativo do parênquima pulmonar (RADZIKOWSKA E, 2017). Já a RB-ILD é geralmente insidiosa com dispneia ao esforço, chiado sintomático e tosse persistente (SIEMINSKA A e KUZIEMSKI K, 2014), por outro lado, há relatos de que a maioria dos acometidos apresentam-se assintomáticos, apesar de terem prejuízos fisiológicos mínimos e subclínicos (WALSH SLF, et al., 2015). Estertores em "velcro" são audíveis em $76 \%$ dos pacientes e raramente a doença tem expressão clínica exacerbada, destarte, o paciente não possuiu qualquer alteração no exame físico respiratório (RODRIGUES SCS, et al., 2004).

A TC de alta resolução mostra, de forma clara, a presença dos nódulos característicos da LCH, distribuídos bilateralmente, com predomínio nos lobos médios e superiores do pulmão (GIRSCHIKOFSKY M, et al., 2013), situação que se aplica ao caso do paciente. A TC também possibilita melhor visualização e caracterização das lesões císticas e nodulares da LCH, ao se comparar a TC com radiografia de tórax, já que a primeira torna possível discriminar se as paredes dos cistos ou nódulos são finas ou espessas (RODRIGUES RS, et al., 2011).

Sabe-se que o pulmão é um grande sítio de metástase, especialmente do câncer de tireoide, através da drenagem linfática compartilhada, apresentando-se na TC comumente como nódulos multifocais. Portanto, o exame imuno-histoquímico se faz importante para diferenciar o câncer metastático de pulmão de outras afecções similares (ZHENG M, 2016). Apesar de negativo para malignidade, o exame imuno-histoquímico do paciente revelou células $C D 1 a+$, que são relacionadas à ativação das células $T$ na resposta imune (LA ROCCA G, et al., 2004; YUAN X, et al., 2019).

Pessoas em uso de tabaco e que tenham enfisema pulmonar tem maior expressividade de células CD1a+, visto que a fumaça do cigarro aumenta a sobrevida das células dendríticas, além do maior recrutamento de componentes do sistema imune promovido pela patogênese da DPOC (LIAO SX, et al., 2015; VASSALLO R, et al., 2010).

A biópsia realizada pelo paciente mostra o acúmulo de lesões nos lobos superiores do pulmão e, a partir do exame histológico, evidencia o infiltrado inflamatório com a formação de granulomas e presença de macrófagos pigmentados (ELIA D, et al., 2015; MONSEREENUSORN C e RODRIGUEZ-GALINDO C, 2015; RADZIKOWSKA E, 2017). O caso em questão apresentou os mesmos achados descritos na literatura.

A PLCH e a RB-ILD têm a interrupção do uso do cigarro como terapia mais eficiente, resultando na estabilização e melhoria dos sintomas, e caso não ocorra, há a possibilidade do uso de corticosteroides. Pacientes que continuam a fumar também podem ter um curso clínico estável, não havendo desfecho fatal relacionado às doenças (KONOPKA KE e MYERS JL, 2018; MARGARITOPOULOS GA, et al., 2015). Entretanto, ao se avaliar o prognóstico a longo prazo, a sobrevida dos pacientes tende a aumentar quando se cessa o uso do cigarro (TOMA CL, et al., 2017). Portanto, recomendou-se ao nosso paciente cessar uso do tabaco, demarcando regressão das lesões em uma nova TC realizada após 12 meses.

Em conclusão, descrevemos um caso cujo diagnóstico diferencial foi imprescindível para se definir a conduta terapêutica adequada e evitar diagnósticos incorretos. As duas patologias apresentadas, RB-ILD e $\mathrm{PLCH}$, são afecções de baixa prevalência na população em geral e, portanto, podem passar despercebidas na hipótese de não ocorrer a devida investigação pelos exames de imagem e histopatológicos adequados. Faz-se mister, para o aperfeiçoamento da prática clínica, o domínio do conteúdo exposto como forma de rastreio de tais doenças. 


\section{REFERÊNCIAS}

1. CHURG A, et al. Respiratory bronchiolitis/interstitial lung disease: fibrosis, pulmonary function, and evolving concepts. Archives of pathology \& laboratory medicine, 2010; 134(1): 27-32.

2. SOUSA VMLD, CARVALHO L. Heterogeneity in Lung Cancer. Pathobiology, 2018; 85(1-2): 96-107.

3. DEMARTINO E, et al. Langerhans Cell Histiocytosis and Other Histiocytic Diseases of the Lung. Clinics in Chest Medicine, 2016; 37(3): 421-430.

4. ELIA D, et al. European Journal of Internal Medicine Pulmonary Langerhans cell histiocytosis : A comprehensive analysis of 40 patients and literature review. European Journal of Internal Medicine, 2015; 26(5): 1-6.

5. FRANKS TJ, GALVIN JR. Smoking-related “'interstitial'” lung disease. Archives of Pathology and Laboratory Medicine, 2015; 139(8): 974-977.

6. GIRSCHIKOFSKY M, et al. Management of adult patients with Langerhans cell histiocytosis: Recommendations from an expert panel on behalf of Euro-Histio-Net. Orphanet Journal of Rare Diseases, 2013; 8(1): 1-11.

7. KÄRKKÄINEN M, et al. Effect of smoking and comorbidities on survival in idiopathic pulmonary fibrosis. Respiratory Research, 2017; 18(160): 1-10.

8. KONOPKA KE, MYERS JL. A review of smoking-related interstitial fibrosis, respiratory bronchiolitis, and desquamative interstitial pneumonia: Overlapping histology and confusing terminology. Archives of Pathology and Laboratory Medicine, 2018; 142(10): 1177-1181.

9. LA ROCCA G, et al. CD1a and antitumour immune response. Immunology Letters, 2004; 95(1): 1-4.

10. LIAO SX, et al. Cigarette smoke affects dendritic cell maturation in the small airways of patients with chronic obstructive pulmonary disease. Molecular Medicine Reports, 2015; 11(1): 219-225.

11. LORILLON G, TAZI A. How I manage pulmonary Langerhans cell histiocytosis. Eur Respir Rev, $2017 ; 26$ : 1-14.

12. MARGARITOPOULOS GA, et al. Smoking and interstitial lung diseases. European Respiratory Review, 2015; 24(137): 428-435.

13. MARGARITOPOULOS GA, et al. Smoking-related idiopathic interstitial pneumonia: A review. Respirology, 2016; 21(1): 57-64.

14. MONSEREENUSORN C, RODRIGUEZ-GALINDO C. Clinical Characteristics and Treatment of Langerhans Cell Histiocytosis. Hematology/Oncology Clinics of North America, 2015; 29(5): 853-873.

15. NASIM F, et al. Lung Cancer. Medical Clinics of North America, 2019; 103(3): 463-473.

16. PAIVA-OLIVEIRA EL, et al. Inflamassoma e sua repercussão clínica: revisão da literatura. Revista de Ciências Médicas e Biológicas, 2012; 11(1): 96-102.

17. PAPPAS, K. Bronchiolitis and bronchial disorders in interstitial lung disease. Current Opinion in Pulmonary Medicine, 2011; 17(5): 316-324.

18. PURANDARE NC, RANGARAJAN V. Imaging of lung cancer: Implications on staging and management. Indian Journal of Radiology and Imaging, 2015; 25(2): 109-120.

19. RADZIKOWSKA E. Pulmonary Langerhans' cell histiocytosis in adults. Advances in Respiratory Medicine, 2017; 85(5): 277-289.

20. RODRIGUES RS, et al. High-resolution computed tomography findings in pulmonary Langerhans cell histiocytosis. Radiol Bras., 2011; 44(4): 225-232.

21. RODRIGUES SC, et al. Respiratory bronchiolitis-associated interstitial lung disease. J Bras Pneumol, 2004; 30(6): 574-580.

22. SIEMINSKA A, KUZIEMSKI K. Respiratory bronchiolitis-interstitial lung disease. Orphanet Journal of Rare Diseases, $2014 ; 9(1): 1-7$.

23. TOMA CL, et al. Respiratory bronchiolitis-associated interstitial lung disease - An unexpected form of idiopathic interstitial pneumonia in a young male. Romanian Journal of Morphology and Embryology, 2017; 58(1): $261-265$.

24. VASSALLO R, et al. Cigarette smoke promotes dendritic cell accumulation in COPD; a Lung Tissue Research Consortium study. Respiratory Research, 2010; 11(45): 1-13.

25. WALSH SLF, et al. Interstitial lung disease related to smoking: Imaging considerations. Current Opinion in Pulmonary Medicine, 2015; 21(4): 407-416.

26. WELLS AU, et al. Respiratory bronchiolitis associated interstitial lung disease (RB-ILD) presenting with haemoptysis. Respirology, 2003; 5(4): 385-387.

27. YUAN X, et al. Cigarette smoke-induced reduction of C1q promotes emphysema. JCI Insight, 2019; 4(13): 1-17.

28. ZHENG M. Classification and Pathology of Lung Cancer. Surgical Oncology Clinics of North America, 2016; 25(3): 447-468. 